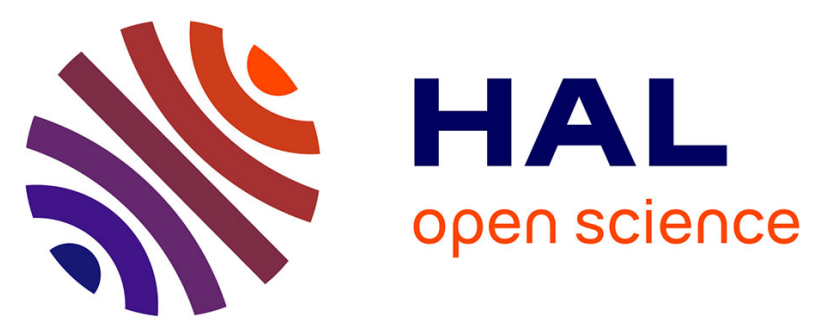

\title{
The effect of hexose ratios on metabolite production in Saccharomyces cerevisiae strains obtained from the spontaneous fermentation of mezcal
}

Amanda Alejandra Oliva Hernandez, Patricia Taillandier, Diana Reséndez Pérez, José A. Narváez Zapata, Claudia Patricia Larralde Corona

\section{To cite this version:}

Amanda Alejandra Oliva Hernandez, Patricia Taillandier, Diana Reséndez Pérez, José A. Narváez Zapata, Claudia Patricia Larralde Corona. The effect of hexose ratios on metabolite production in Saccharomyces cerevisiae strains obtained from the spontaneous fermentation of mezcal. Antonie van Leeuwenhoek, 2013, vol. 103, pp. 833-843. 10.1007/s10482-012-9865-1 . hal-00975247

\section{HAL Id: hal-00975247 https://hal.science/hal-00975247}

Submitted on 8 Apr 2014

HAL is a multi-disciplinary open access archive for the deposit and dissemination of scientific research documents, whether they are published or not. The documents may come from teaching and research institutions in France or abroad, or from public or private research centers.
L'archive ouverte pluridisciplinaire HAL, est destinée au dépôt et à la diffusion de documents scientifiques de niveau recherche, publiés ou non, émanant des établissements d'enseignement et de recherche français ou étrangers, des laboratoires publics ou privés. 


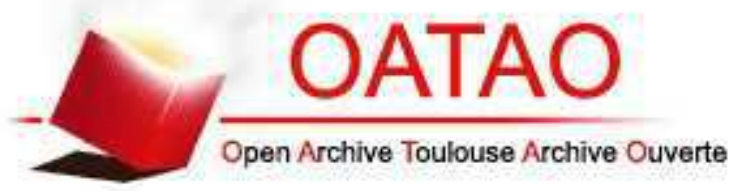

\section{Open Archive Toulouse Archive Ouverte (OATAO)}

OATAO is an open access repository that collects the work of Toulouse researchers and makes it freely available over the web where possible.

This is an author-deposited version published in: http://oatao.univ-toulouse.fr/ Eprints ID: 9943

To link to this article: DOI:10.1007/s10482-012-9865-1

http://dx.doi.org/10.1007/s10482-012-9865-1

\section{To cite this version:}

Oliva Hernandez, Amanda Alejandra and Taillandier, Patricia and Reséndez Pérez, Diana and Narváez Zapata, José A. and Larralde Corona, Claudia Patricia The effect of hexose ratios on metabolite production in Saccharomyces cerevisiae strains obtained from the spontaneous fermentation of mezcal. (2013) Antonie van Leeuwenhoek, vol. 103 ( $\left.{ }^{\circ} 4\right)$. pp. 833-843. ISSN 0003-6072

Any correspondence concerning this service should be sent to the repository administrator: staff-oatao@ listes-diff.inp-toulouse.fr 


\title{
The effect of hexose ratios on metabolite production in Saccharomyces cerevisiae strains obtained from the spontaneous fermentation of mezcal
}

\author{
Amanda A. Oliva Hernández • Patricia Taillandier • Diana Reséndez Pérez • \\ José A. Narváez Zapata • Claudia Patricia Larralde Corona
}

\begin{abstract}
Mezcal from Tamaulipas (México) is produced by spontaneous alcoholic fermentation using Agave spp. musts, which are rich in fructose. In this study eight Saccharomyces cerevisiae isolates obtained at the final stage of fermentation from a traditional mezcal winery were analysed in three semisynthetic media. Medium M1 had a sugar content of $100 \mathrm{~g}^{-1}$ and a glucose/fructose $(\mathrm{G} / \mathrm{F})$ of 9:1. Medium M2 had a sugar content of $100 \mathrm{~g}^{-1}$ and a $\mathrm{G} / \mathrm{F}$ of 1:9. Medium M3 had a sugar content of $200 \mathrm{~g}^{-1}$ and a G/F of $1: 1$. In the three types of media tested, the highest ethanol yield was obtained from the glucophilic strain LCBG-3Y5, while strain LCBG3 Y8 was highly resistant to ethanol and the most fructophilic of the mezcal strains. Strain LCBG-3Y5
\end{abstract}

\footnotetext{
A. A. Oliva Hernández · J. A. Narváez Zapata ·

C. P. Larralde Corona $(\bowtie)$

Laboratorio de Biotecnología Industrial, Instituto Politécnico Nacional, Centro de Biotecnología Genómica, Blvd del Maestro s/n esq. Elías Piña Col. Narciso Mendoza, C.P. 88710 Reynosa, Tamaulipas, Mexico e-mail: plarralde@ipn.mx

P. Taillandier

Laboratoire de Génie Chimique, INP-ENSIACET,

Université de Toulouse, CNRS 5503, 4 allée Emile

Monso, 31432 Toulouse, France

D. Reséndez Pérez

Facultad de Ciencias Biológicas, Universidad Autónoma de Nuevo León, Monterrey, NL, Mexico
}

produced more glycerol $\left(4.4 \mathrm{~g} \mathrm{l}^{-1}\right)$ and acetic acid $\left(1 \mathrm{~g} \mathrm{l}^{-1}\right)$ in $\mathrm{M} 2$ than in $\mathrm{M} 1$ (1.7 and $0.5 \mathrm{~g} \mathrm{l}^{-1}$, respectively), and the ethanol yields were higher for all strains in M1 except for LCBG-3Y5, -3Y8 and the Fermichamp strain. In medium M3, only the Fermichamp strain was able to fully consume the $100 \mathrm{~g}$ of fructose $1^{-1}$ but left a residual $32 \mathrm{~g}$ of glucose $1^{-1}$. Regarding the hexose transporters, a high number of amino acid polymorphisms were found in the Hxt1p sequences. Strain LCBG-3Y8 exhibited eight unique amino acid changes, followed by the Fermichamp strain with three changes. In Hxt3p, we observed nine amino acid polymorphisms unique for the Fermichamp strain and five unique changes for the mezcal strains.

Keywords Saccharomyces cerevisiae - Mezcal . Agave must · Fructose - Glucose $\cdot$ Hexose transporter

\section{Introduction}

Mezcal is a traditional Mexican spirit, which is produced from the alcoholic fermentation of cooked Agave spp. musts and distilled. The processing conditions differ from producer to producer, and the raw material (cooked agave must) comes from different species of the Agave genus (Arrizon et al. 2006). As the fructans and saponins vary among Agave 
species, this in fact determines which type(s) of microflora, particularly yeasts, can thrive in these musts (Verdugo Valdez et al. 2011). Another important factor is the temperature at which the fermentation is carried out, as this is not controlled in the most rustic distilleries and depends on the geographical characteristics of the production site; these temperatures typically range from 20 to $40{ }^{\circ} \mathrm{C}$. In addition, defined (commercial) inocula are seldom used. Hence, this fermentation is indeed spontaneous and environmentdependent.

Diluted Tamaulipas agave musts used for the fermentation are characterised by a high concentration of fructose (up to $90 \mathrm{~g}$ of fructose $1^{-1}$ and only approximately $10 \mathrm{~g}$ of glucose $1^{-1}$ ), as also observed by Arroyo-López et al. (2009) for the mezcal produced in Durango (México). This low G/F ratio (0.11) makes this system very different from other important musts such as wine, which has a G/F of 1.0 (Guillaume et al. 2007). This particular characteristic of agave must may favour the natural occurrence of fructophilic Saccharomyces cerevisiae yeasts, which have a higher than normal fructose uptake rate, ideally evidenced by the full consumption of fructose or, as used in this work for practicality, by a residual fructose concentration equal to or lower than $2 \%$ of the initial fructose concentration in the medium at the end of fermentation.

The fructophilic phenotype of some S. cerevisiae isolates has been associated with the presence of specific functional hexose transporters, as these are involved in the first steps of simple sugar catabolism by introducing the available hexoses throughout the cellular membrane (Reifenberger et al. 1997). In $S$. cerevisiae, 18 different hexose transporter proteins have been reported, in addition to two closely related glucose sensors, Rgt2p and Snf3p (Luyten et al. 2002), which share similar terminal amino acid sequences. Hexose transporter proteins 1-4, 6 and 7 are the main carriers reported in $S$. cerevisiae and can take up glucose, fructose and mannose (Reifenberger et al. 1997), thereby displaying diverse hexose specificities and affinities (Guillaume et al. 2007; Saloheimo et al. 2007). Of all functional carriers reported, Hxt1p and Hxt $3 p$ seem to be the most relevant from the enological point of view, due to the high hexose (glucose and fructose) concentrations typical of wine musts (Luyten et al. 2002). Both Hxt1p and Hxt3p have been shown to have a low affinity for glucose, with $\mathrm{K}_{\mathrm{m}}$ values of approximately 100 and $60 \mathrm{mM}$, respectively (Reifenberger et al. 1997), and the peaks of gene expression profiles coincide with a higher rate of fructose consumption (Guillaume et al. 2007; Karpel et al. 2008). Moreover, the expression of these two transporters alone is enough to achieve a full synthetic wine fermentation, demonstrated in the enologically-derived strain V5 (Luyten et al. 2002). This finding has been related to the fact that the HXT1 gene expression peaks during the lag phase and early exponential phase (high hexose concentrations) during wine fermentation (Luyten et al. 2002; Karpel et al. 2008), while HXT3 is expressed at the onset of the stationary phase (Luyten et al. 2002; Maier et al. 2002) when the ethanol concentration is already high and deleterious to cell membranes and proteins, including most carriers. However, it has also been reported that deletion of Hxt3p in the wine strain UCD932 is linked to an inability to complete the fermentation when ethanol is exogenously added from the start of the culture (Karpel et al. 2008). Therefore, in addition to its expression at high hexose concentrations, Hxt3p may also be linked to superior ethanol resistance in some strains. If this is the case, these yeasts would be good candidates for use as inocula in stuck wine fermentations.

Accordingly, this work presents for the first time the productive diversity of $S$. cerevisiae isolates obtained from spontaneously fermenting agave musts of the mezcal produced in the Tamaulipas state of Mexico, focusing on the impact of the glucose/ fructose $(\mathrm{G} / \mathrm{F})$ ratio and the glucose/fructose concentrations on the fructophilic phenotype, ethanol resistance and metabolite productivity of the isolates. Finally, an analysis of the predicted amino acid sequences of HXT1 and HXT3 was conducted, and the relationship between the polymorphisms of these genes and the residual fructose levels after fermentation is discussed.

\section{Materials and methods}

\section{Microorganisms}

The rustic "El Palmar" mezcal winery at the "Sierra de San Carlos" in Tamaulipas, Mexico was sampled (environment and must) at different locations and at different fermentation times, and a total of 51 different 
yeasts belonging to nine species were isolated (data not shown). S. cerevisiae yeast was isolated from day 1 (2 isolates) onwards, and at the end of fermentation (day 6), the maximum number of members of this species (10) was recorded. The yeasts were isolated either in potato dextrose agar (LCBG-D series) or in yeast extract peptone dextrose agar (LCBG-Y series). Additionally, three $S$. cerevisiae isolates were obtained from fruit flies (Drosophila melanogaster) collected from the surface of the fermenting must at the beginning of the process (data not shown). A working set of eight $S$. cerevisiae isolates, all collected on day 6 of agave must fermentation, were used in this work, and their 26S nucleotide sequences are available in GenBank with the following accession numbers: LCBG-3Y5 (JQ824869), LCBG-3D2 (JQ824871), LCBG-3Y3 (JQ824872), LCBG-3D3 (JQ824873), LCBG-3Y8 (JQ824874), LCBG-3Y4 (JQ824875), LCBG-3D6 (JQ824876) and LCBG-3Y2 (JQ824877). The commercial wine strain Fermichamp (DSM Food Specialties B.V., The Netherlands) was used as a fructophilic control, according to Guillaume et al. (2007).

\section{Culture media}

All experiments were carried out in $250 \mathrm{ml}$ flasks containing $50 \mathrm{ml}$ of one of three different types of media, which were prepared to have no nitrogen limitation for fermentation, using the basal composition reported by Taillandier et al. (2007) as follows: $1 \mathrm{~g}$ of yeast extract, $2 \mathrm{~g}$ of $\left(\mathrm{NH}_{4}\right)_{2} \mathrm{SO}_{4}, 0.4 \mathrm{~g}$ of $\mathrm{MgSO}_{4} \cdot 7 \mathrm{H}_{2} \mathrm{O}$ and $5 \mathrm{~g}$ of $\mathrm{KH}_{2} \mathrm{PO}_{4}$, all dissolved in 1 litre of distilled water with the $\mathrm{pH}$ adjusted to 5, as this is the average $\mathrm{pH}$ observed in the diluted agave musts. For the carbon source, we tested three types of media with different initial $\mathrm{G} / \mathrm{F}$ ratios and total sugar quantities. Medium M1 had a G/F ratio of 9:1 (high glucose medium) and an initial hexose concentration of $100 \mathrm{~g} \mathrm{l}^{-1}$. Medium M2 had a $\mathrm{G} / \mathrm{F}$ of 1:9 (to simulate a typical Tamaulipas agave must hexose ratio, according to our HPLC measurements) and an initial hexose concentration of $100 \mathrm{~g} \mathrm{l}^{-1}$. Medium M3 had a $\mathrm{G} / \mathrm{F}$ ratio of $1: 1$ at an initial sugar concentration of $200 \mathrm{~g} \mathrm{l}^{-1}$ (to simulate the hexose concentration of grape must). All experiments employed yeast inoculums of $3 \times 10^{6}$ cells $\mathrm{ml}^{-1}$ and incubation at $30{ }^{\circ} \mathrm{C}$ without shaking (except at sampling times), and the results are presented as the mean of three replicates.

\section{Biomass quantification}

Biomass production was assessed by the optical density at $600 \mathrm{~nm}$ using a spectrophotometer (model U-2000TM Hitachi, Japan) after diluting the sample as needed and using fresh uninoculated medium as the blank. The final dry weight reached by the yeasts was measured by centrifuging $10 \mathrm{ml}$ at $2,500 \mathrm{rpm}$ and $10{ }^{\circ} \mathrm{C}$ for $10 \mathrm{~min}$, rinsing the pellet twice with distilled water and allowing it to dry to a constant weight in a humidity analyser (model Precisa HA60, Zurich, Switzerland). The results are presented as the mean of three replicates, and the standard deviations were always less than $10 \%$.

Sugar consumption and metabolite quantification

The consumption of hexoses (D-glucose and D-fructose) and the production of metabolites (glycerol, acetic acid, lactic acid and ethanol) were measured by HPLC as reported by Narváez-Zapata et al. (2010). Metabolite final concentrations are presented as the mean of three replicates.

Ethanol resistance

The experiments were carried out in triplicate, according to Pina et al. (2004). Minor changes to the reported protocol were introduced, as the initial cell concentration of the experiment was one order of magnitude lower $\left(3 \times 10^{6}\right.$ cells $\left.\mathrm{ml}^{-1}\right)$ than that reported by these authors. Briefly, $100 \mathrm{ml}$ of medium M2 $(\mathrm{G} / \mathrm{F}=1: 9)$, prepared as stated above, was inoculated with a loop of the tested yeast and incubated at $125 \mathrm{rpm}$ for $24 \mathrm{~h}$ at $30{ }^{\circ} \mathrm{C}$. Subsequently, an aliquot of $25 \mathrm{ml}$ was withdrawn and centrifuged for 10 min at 3,000 rpm (Allegra 6G centrifuge, Beckman Coulter, Japan), and the pellet was resuspended in $25 \mathrm{ml}$ of YM broth (Difco). An initial sample was taken (time 0 ), and the needed volume of absolute ethanol to achieve an ethanol concentration of $25 \%$ v/v was added, with additional samples collected every $30 \mathrm{~s}$. Each sample was serially diluted in sterile Ringer's solution to perform the plate count technique in triplicate by counting the colonies on YM agar plates after a $72 \mathrm{~h}$ incubation at $29{ }^{\circ} \mathrm{C}$. The results were compared with the viable counts obtained from the initial sample. Plate count standard deviations were always less than $10 \%$. 


\section{DNA isolation}

The cells used for DNA extraction were grown for $18 \mathrm{~h}$ at $29{ }^{\circ} \mathrm{C}$ in $4 \mathrm{ml}$ of YPD medium $(1 \%$ yeast extract, $2 \%$ bacto-peptone and $2 \%$ glucose, adjusted to $\mathrm{pH}$ 6) on a rotary shaker at $200 \mathrm{rpm}$ and harvested by centrifugation. The cells were washed twice with distilled water, resuspended in $5 \mathrm{ml}$ of distilled water, and $1 \mathrm{ml}$ of the suspension was placed into a microcentrifuge tube. After centrifugation, the excess water was decanted from the tube, and the packed cells were frozen in liquid nitrogen for $30 \mathrm{~min}$. DNA isolation for PCR was performed by a modified version of the sodium dodecyl sulphate protocol of Raeder and Broda (1985). The cells were suspended in $1 \mathrm{ml}$ of extraction buffer $[200 \mathrm{mM}$ Tris- $\mathrm{HCl}(\mathrm{pH} 8.5)$, $250 \mathrm{mM} \mathrm{NaCl}, 25 \mathrm{mM}$ EDTA (pH 8.0) and $0.5 \%$ sodium dodecyl sulphate] and extracted with phenolchloroform and chloroform. The DNA was precipitated from the aqueous phase by adding $500 \mu \mathrm{l}$ of isopropanol and pelleted by centrifugation for $3 \mathrm{~min}$ at $14,000 \mathrm{rpm}$. The pellet was washed gently with $70 \%$ ethanol, resuspended in $50 \mu \mathrm{l}$ of sterile milliQ water and dissolved by a $5 \mathrm{~min}$ incubation at $58{ }^{\circ} \mathrm{C}$.

Sequencing of the hexose transporters HXT1 and HXT3

Gene amplification of HXT1 and HXT3 was conducted first by using the following primers reported by Ramakrishnan et al. (2007): 5' GTGAAAGTCAA GTGCAACCC $3^{\prime}$ and PRHXT1 5' CGGTCAACGG TGTACAGAG $3^{\prime}$ for HXT1 and PFHXT3 5' GATT TCCAAGCTGAGGCCG $3^{\prime}$ and PRHXT3 $5^{\prime}$ ACATG GCCGGCTTACCAGTG 3' for HXT3. In addition, HXT1 and HXT3 sequences available from GenBank were used to design a new set of specific primers for the amplification of the whole HXT1 and HXT3 sequences. The designed primers for HXT1 are JAHXT1F 5' ATGAGAGCCGCTGGTACTGCATC T $3^{\prime}$ and JAHXT1R 5' CTATTTCCTGCTAAACA AACTCTTG $3^{\prime}$. The primers for HXT3 are FHXT3 J 5'ATTTCTGAAGTCGCTCCTAAGG $3^{\prime}$ and RHX T3 J 5' ACATAACAGCAGACCATACC $3^{\prime}$. The reaction mix was the same for both genes and contained $0.5 \mathrm{mM}$ per primer, $10 \mathrm{mM}$ deoxynucleotides, $1.5 \mathrm{mM} \mathrm{MgCl}_{2}, 0.04 \mathrm{U}$ of Taq DNA polymerase (Promega, Madison WI, USA) and $1 \times$ buffer. The amplification was performed with a $5 \mathrm{~min}$ denaturalisation step at $94{ }^{\circ} \mathrm{C}$ followed by 35 cycles consisting of $30 \mathrm{~s}$ at $94{ }^{\circ} \mathrm{C}, 30 \mathrm{~s}$ at $63{ }^{\circ} \mathrm{C}$ and $30 \mathrm{~s}$ at $72{ }^{\circ} \mathrm{C}$ and a final extension of $7 \mathrm{~min}$ at $72{ }^{\circ} \mathrm{C}$. The PCR products were purified using the Wizard System (Promega, Madison, WI, USA) according to the manufacturer's instructions. Direct sequencing was conducted with the Sequence BigDye ${ }^{\circledR}$ Terminator v3.1 Cycle Sequencing Kit (Life Technologies, Foster City CA, USA) on an ABI PRISM 3130 capillary automated sequencer (Applied Biosystems, Foster City CA, USA). The sequence of the HXT1 of the Fermichamp control strain was obtained as described above, and its HXT3 sequence was taken from Guillaume et al. (2007). Sequence analysis was performed using the basic local alignment search tool (BLAST) program (Altschul et al. 1990), and comparisons were performed manually in relation to the reference strain $S$. cerevisiae $\mathrm{S} 228$ c accession numbers YHR094C and YHR094C for HXT1 and HXT3, respectively, using the BioEdit program (http://www. mbio.ncsu.edu/BioEdit/bioedit.html). Finally, the polymorphism localisation was assessed using the PSIPRED server (Buchan et al. 2010) found at http:// bioinf.cs.ucl.ac.uk/psipred/.

\section{Results}

The effect of the hexose ratio on metabolite production in $S$. cerevisiae strains

All yeasts isolated were able to produce a wide range of ethanol concentrations (data not shown). In this work, only eight of $15 \mathrm{~S}$. cerevisiae isolates were chosen from the LCBG-3D\# series (D2, D3 and D6) and the LCBG-3Y\# series (Y2, Y3, Y4, Y5 and Y8). These isolates were representative of the phenotypic variety found during the final stage of mezcal fermentation and differed in their growth kinetics and other productive characteristics as their final dry weight and production of glycerol and organic acids. From the optical density profiles, we observed that the control strain Fermichamp behaved similarly to the Y series isolates in medium M1 (high glucose, Fig. 1a), but in medium M2 (agave-like, Fig. 1b), its optical density profile resembled that of the D series. Notably, according to the optical density, the D series isolates reached a lower final dry weight concentration $\left(0.65 \mathrm{~g} \mathrm{l}^{-1}\right)$ than the $\mathrm{Y}$ series isolates $\left(1.87 \mathrm{~g} \mathrm{l}^{-1}\right)$ in 
both types of media, except for LCBG-3Y2 $\left(0.75 \mathrm{~g} \mathrm{l}^{-1}\right)$.

For evaluation of the hexose consumption and metabolite production in M1 and M2 media (Tables $1,2)$, the data were sorted by strain based on the highest residual fructose (glucophilic) to the lowest observed in the agave-like medium M2. A strain was considered fructophilic if the residual fructose concentration was equal to or lower than $2 \%$ of the initial fructose concentration in the medium at the end of fermentation $(120 \mathrm{~h})$; this was equivalent to a final fructose concentration equal to or lower than $0.2 \mathrm{~g} \mathrm{l}^{-1}$

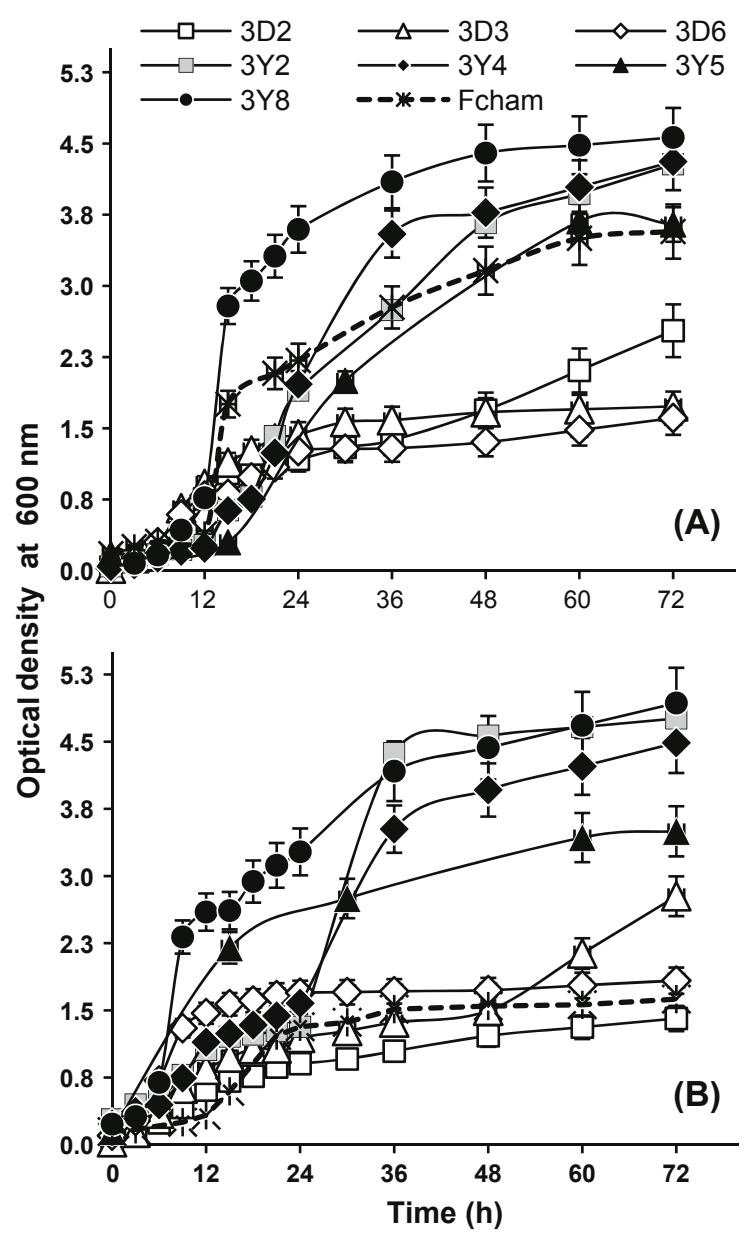

Fig. 1 Growth kinetics of seven out of eight S. cerevisiae mezcal strains plus the control fermichamp strains, assessed as the change in the optical density (at $600 \mathrm{~nm}$ ) of the cultures in media. a Medium M1 (G/F = 9:1, high glucose) and b medium $\mathrm{M} 2$ ( $\mathrm{G} / \mathrm{F}=1: 9$, agave-like), both at an initial hexose concentration of $100 \mathrm{~g}^{-1}$. As the strains LCBG-3Y3 and LCBG-3Y5 behaved the same way, only the latter was included in the graph for clarity for medium M1, equal to or lower than $1.8 \mathrm{~g} \mathrm{l}^{-1}$ for medium M2 and equal to or lower than $2 \mathrm{~g} \mathrm{l}^{-1}$ for medium M3 (at $240 \mathrm{~h}$ ). In terms of the fructose utilisation, isolates LCBG-3D2 and LCBG-3D3 left the highest residual hexoses in both types of media, while only strains LCBG-3Y2 and LCBG-3Y8 (plus 3 Y4 only in medium M2) utilised enough fructose in both types of media to be considered fructophilic, in addition to the control strain Fermichamp. Notably, however, these strains were not the most productive in terms of ethanol yield, an important parameter in the consideration of potential inoculants of agave must or other fermentation substrates rich in fructose. Glucophilic strains LCBG-3Y3 and -3Y5 had the highest ethanol yields in both M1 and M2 media, but having contrasting glycerol and acid lactic productions.

The performance of the mezcal strains in the grape must like medium M3 (G/F 1:1, at $200 \mathrm{~g} \mathrm{l}^{-1}$ of total hexoses) was assessed only for three different mezcal $S$. cerevisiae strains that were selected based on their contrasting phenotypes in M1 and M2 media. The strains chosen were LCBG-3Y3 and -3Y5, which had the highest ethanol yields in both types of media, and isolate LCBG-3Y8 which was fructophilic in both types of media. The commercial strain Fermichamp was used as a control strain. For the four yeasts tested, we observed that while the glucose concentration in medium M3 followed a smooth first-order decay, the fructose was consumed in a two-step mode, lasting the first step up to $72 \mathrm{~h}$, most likely due to a period of adaptation towards the decreasing $\mathrm{G} / \mathrm{F}$ ratio and increasing ethanol concentration, and approximately coinciding with the time when $50 \%$ of the glucose had been consumed, as also observed by Berthels et al. (2004). These profiles were clearer when the concentrations were presented as a percentage of the hexose consumed versus time (Fig. 2). Although the two steps are clearly defined (full triangles), the fructose consumption kinetics can be linearly fitted $\left(R^{2} \geq 0.91\right.$ ), while for glucose consumption (empty circles), a logarithmic function rendered the best fit $\left(R^{2} \geq 0.96\right)$.

The control strain Fermichamp was the only yeast able to completely use the fructose in medium M3 after 11 days of fermentation, but it had the lowest glucose consumption. Additionally, at the end of fermentation, the total residual sugar was higher $(32 \mathrm{~g}$ of glucose $1^{-1}$ ) for this control strain than for the mezcal strains, which had total residual sugar 
Table 1 Productive performance of mezcal S. cerevisiae isolates at the end of fermentation on the high glucose medium $\mathrm{M} 1(\mathrm{G} / \mathrm{F}=9: 1)$ at $100 \mathrm{~g} \mathrm{l}^{-1}$ of initial hexoses

\begin{tabular}{lllllllll}
\hline ID & $\begin{array}{l}\text { Final dry } \\
\text { weight } \\
\left(\mathrm{g} \mathrm{l}^{-1}\right)\end{array}$ & $\begin{array}{l}\text { Residual } \\
\text { fuctose } \\
\left(\mathrm{g}^{-1}\right)\end{array}$ & $\begin{array}{l}\text { Residual } \\
\text { glucose } \\
\left(\mathrm{g} \mathrm{l}^{-1}\right)\end{array}$ & $\begin{array}{l}\text { Glycerol } \\
\left(\mathrm{g} \mathrm{l}^{-1}\right)\end{array}$ & $\begin{array}{l}\text { Acetic acid } \\
\left(\mathrm{g} \mathrm{l}^{-1}\right)\end{array}$ & $\begin{array}{l}\text { Lactic acid } \\
\left(\mathrm{g}^{-1}\right)\end{array}$ & $\begin{array}{l}\text { EtOH } \\
\left(\mathrm{g} \mathrm{l}^{-1}\right)\end{array}$ & $\begin{array}{l}\mathrm{Y}_{\text {EtOH/S }} \\
\left(\mathrm{g} \mathrm{g}^{-1}\right)\end{array}$ \\
\hline LCBG-3D2 & $0.6 \pm 0.02$ & $3.0 \pm 0.4$ & $18.1 \pm 1.2$ & $5.3 \pm 0.54$ & $0.70 \pm 0.01$ & $0.75 \pm 0.15$ & $31.2 \pm 1.30$ & 0.39 \\
LCBG-3D3 & $0.5 \pm 0.06$ & $9.7 \pm 0.3$ & $5.9 \pm 1.1$ & $4.9 \pm 0.65$ & $0.46 \pm 0.03$ & $0.60 \pm 0.01$ & $36.4 \pm 0.80$ & 0.43 \\
LCBG-3D6 & $0.7 \pm 0.01$ & $1.8 \pm 0.4$ & $6.8 \pm 1.2$ & $5.8 \pm 0.40$ & $0.50 \pm 0.02$ & $0.50 \pm 0.1$ & $35.6 \pm 1.80$ & 0.39 \\
LCBG-3Y5 & $2.3 \pm 0.03$ & $0.5 \pm 0.9$ & $1.6 \pm 1.0$ & $1.7 \pm 0.05$ & $0.40 \pm 0.0$ & $0.75 \pm 0.01$ & $43.9 \pm 3.2$ & 0.45 \\
LCBG-3Y3 & $1.8 \pm 0.03$ & $1.2 \pm 0.6$ & $2.8 \pm 0.2$ & $3.8 \pm 0.50$ & $0.70 \pm 0.01$ & $0.80 \pm 0.07$ & $45.2 \pm 1.2$ & 0.47 \\
LCBG-3Y4 & $2.0 \pm 0.08$ & $0.6 \pm 0.2$ & $1.2 \pm 0.2$ & $3.0 \pm 0.30$ & $0.60 \pm 0.03$ & $0.0 \pm 0.0$ & $34.5 \pm 0.83$ & 0.35 \\
LCBG-3Y2 & $0.7 \pm 0.02$ & $0.3 \pm 0.2$ & $0.2 \pm 0.2$ & $4.1 \pm 0.05$ & $0.60 \pm 0.04$ & $0.70 \pm 0.03$ & $35.4 \pm 0.90$ & 0.36 \\
LCBG-3Y8 & $1.3 \pm 0.10$ & $0.2 \pm 0.2$ & $1.0 \pm 0.4$ & $2.9 \pm 0.30$ & $0.50 \pm 0.04$ & $0.50 \pm 0.06$ & $31.5 \pm 0.80$ & 0.32 \\
Fermichamp $^{\mathrm{a}}$ & $0.9 \pm 0.10$ & $0.1 \pm 0.2$ & $0.0 \pm 0.1$ & $3.3 \pm 0.30$ & $0.40 \pm 0.0$ & $1.3 \pm 0.05$ & $39.0 \pm 0.80$ & 0.39 \\
\hline
\end{tabular}

All data are the average values of triplicate experiments, sampled at $120 \mathrm{~h}$

$\mathrm{EtOH}_{\max }$ maximum ethanol production, $\mathrm{Y}_{\mathrm{EtOH} / \mathrm{S}}$ ethanol yield, gram of ethanol produced per gram of sugar (glucose plus fructose) consumed

${ }^{a}$ Fructophilic control strain

Table 2 Productive performance of mezcal S. cerevisiae isolates at the end of fermentation on the agave-like medium $\mathrm{M} 2(\mathrm{G} / \mathrm{F}=1: 9)$ at $100 \mathrm{~g}^{-1}$ of initial hexoses

\begin{tabular}{lllllllll}
\hline ID & $\begin{array}{l}\text { Final dry } \\
\text { weight }\left(\mathrm{g}^{-1}\right)\end{array}$ & \multicolumn{1}{l}{$\begin{array}{l}\text { Residual } \\
\text { fructose }\left(\mathrm{g} \mathrm{l}^{-1}\right)\end{array}$} & $\begin{array}{l}\text { Residual } \\
\text { glucose }\left(\mathrm{g} \mathrm{l}^{-1}\right)\end{array}$ & $\begin{array}{l}\text { Glycerol } \\
\left(\mathrm{g} \mathrm{l}^{-1}\right)\end{array}$ & $\begin{array}{l}\text { Acetic acid } \\
\left(\mathrm{g} \mathrm{l}^{-1}\right)\end{array}$ & \multicolumn{1}{l}{$\begin{array}{l}\text { Lactic acid } \\
\left(\mathrm{g} \mathrm{l}^{-1}\right)\end{array}$} & $\begin{array}{l}\text { EtOH } \\
\left(\mathrm{g}^{-1}\right)\end{array}$ & \multicolumn{1}{l}{$\begin{array}{l}\mathrm{Y}_{\text {EtOH/S }} \\
\left(\mathrm{g} \mathrm{g}^{-1}\right)\end{array}$} \\
\hline LCBG-3D2 & $0.6 \pm 0.06$ & $23.5 \pm 1.4$ & $1.6 \pm 0.4$ & $3.7 \pm 0.3$ & $0.3 \pm 0.04$ & $0.75 \pm 0.3$ & $22.5 \pm 2.5$ & 0.30 \\
LCBG-3D3 & $0.8 \pm 0.02$ & $13.6 \pm 0.7$ & $1.1 \pm 0.3$ & $6.1 \pm 1.1$ & $0.4 \pm 0.02$ & $0.6 \pm 0.1$ & $33.8 \pm 0.9$ & 0.40 \\
LCBG-3D6 & $0.7 \pm 0.08$ & $3.1 \pm 0.26$ & $1.3 \pm 0.4$ & $4.1 \pm 0.6$ & $0.7 \pm 0.06$ & $0.7 \pm 0.1$ & $33.6 \pm 0.4$ & 0.35 \\
LCBG-3Y5 & $2.1 \pm 0.03$ & $4.7 \pm 0.7$ & $1.0 \pm 0.7$ & $4.4 \pm 0.3$ & $0.9 \pm 0.02$ & $1.0 \pm 0.2$ & $47.5 \pm 1.0$ & 0.50 \\
LCBG-3Y3 & $1.9 \pm 0.02$ & $4.0 \pm 0.41$ & $1.1 \pm 0.0$ & $3.0 \pm 1.7$ & $0.9 \pm 0.30$ & $0.0 \pm 0.0$ & $39.0 \pm 0.1$ & 0.41 \\
LCBG-3Y4 & $1.8 \pm 0.10$ & $2.7 \pm 1.1$ & $1.0 \pm 0.0$ & $2.8 \pm 0.3$ & $0.6 \pm 0.00$ & $0.40 \pm 0.1$ & $31.9 \pm 1.4$ & 0.33 \\
LCBG-3Y2 & $0.8 \pm 0.12$ & $2.0 \pm 0.2$ & $1.0 \pm 0.0$ & $2.5 \pm 0.4$ & $0.5 \pm 0.06$ & $0.13 \pm 0.0$ & $27.8 \pm 1.2$ & 0.29 \\
LCBG-3Y8 & $1.7 \pm 0.15$ & $1.2 \pm 0.41$ & $1.0 \pm 0.1$ & $3.9 \pm 0.3$ & $0.7 \pm 0.06$ & $0.8 \pm 0.1$ & $37.2 \pm 4.4$ & 0.38 \\
Fermichamp & $1.0 \pm 0.13$ & $0.3 \pm 0.03$ & $1.0 \pm 0.1$ & $3.6 \pm 0.4$ & $0.4 \pm 0.00$ & $1.3 \pm 0.1$ & $42.0 \pm 1.1$ & 0.43 \\
\hline
\end{tabular}

All data are the average values of triplicate experiments, sampled at $120 \mathrm{~h}$

$\mathrm{EtOH}_{\max }$ maximum ethanol production, $\mathrm{Y}_{\mathrm{EtOH} / \mathrm{S}}$ ethanol yield, gram of ethanol produced per gram of sugar (glucose plus fructose) consumed

${ }^{\mathrm{a}}$ Fructophilic control strain

(almost exclusively fructose) concentrations of $16 \mathrm{~g} \mathrm{l}^{-1}$ for LCBG-3Y3, $13.5 \mathrm{~g} \mathrm{l}^{-1}$ for LCBG-3Y5, and $10 \mathrm{~g} \mathrm{l}^{-1}$ for LCBG-3Y8. The final ethanol production was higher for yeasts LCBG-3Y5 and 3 Y8 $\left(77 \mathrm{~g} \mathrm{l}^{-1}\right)$ than for LCBG-3Y3 $\left(68 \mathrm{~g} \mathrm{l}^{-1}\right)$, and the lowest production was observed in the control strain Fermichamp $\left(62 \mathrm{~g} \mathrm{l}^{-1}\right)$. The final glycerol production levels were practically the same, ranging between 8.5 and $9 \mathrm{~g} \mathrm{l}^{-1}$ for the four yeasts.
Ethanol resistance of selected $S$. cerevisiae mezcal strains

The physiological differences recorded, particularly the ethanol yields and fructose consumption, led us to explore the ethanol resistance of some of the yeasts (Fig. 3). The yeast LCBG-3Y8 showed a superior ethanol resistance compared with the other two mezcal strains and Fermichamp, and this may be related to the 

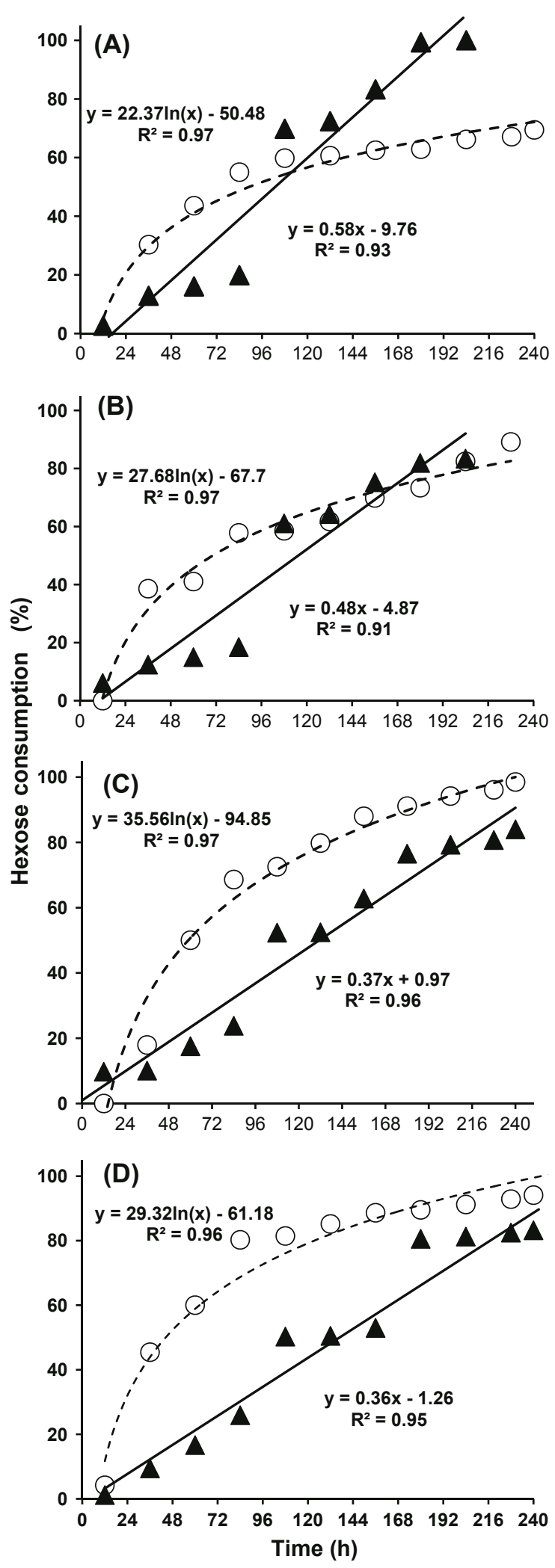

Fig. 2 Percentage of consumed hexoses in the grape-like medium $\mathrm{M} 3(\mathrm{G} / \mathrm{F}=1: 1$, at an initial total concentration of $200 \mathrm{~g}^{-1}$ ) for strains: a Fermichamp (fructophilic control strain) and the LCBG-3Y\# series of mezcal S. cerevisiae strains, b LCBG-3Y8 (the most fructophilic), c LCBG-3Y5 (glucophilic), and d LCBG-3Y3 (glucophilic). Circle Glucose (fit, dotted line), black triangle Fructose (fit, full line). Regression was performed using the Microsoft Excel 2010 ${ }^{\mathrm{TM}}$ correlation functions

differences in the HXT1 and HXT3 gene sequences found in this strain and presented below.

Hexose transporter analysis in S. cerevisiae mezcal strains

The analysis of the predicted amino acid mutations was conducted based on the sequences obtained for the hexose transporter genes HXT1 and HX3 in the selected yeasts. Accordingly, Table 3 shows the amino acid substitutions found in the sequences compared to the reference strain S. cerevisiae S228c. A total of 25 and 15 polymorphisms were detected for Hxt1p and Hxt3p, respectively. The yeasts of the LCBG-3Y\# series exhibited a higher number of unique polymorphisms (14) in the amino acid sequences of Hxtp1 than those unique changes (3) obtained exclusively for Fermichamp. Regarding Hxtp3, we did not find any of the polymorphisms reported for Fermichamp (Guillaume et al. 2007) in

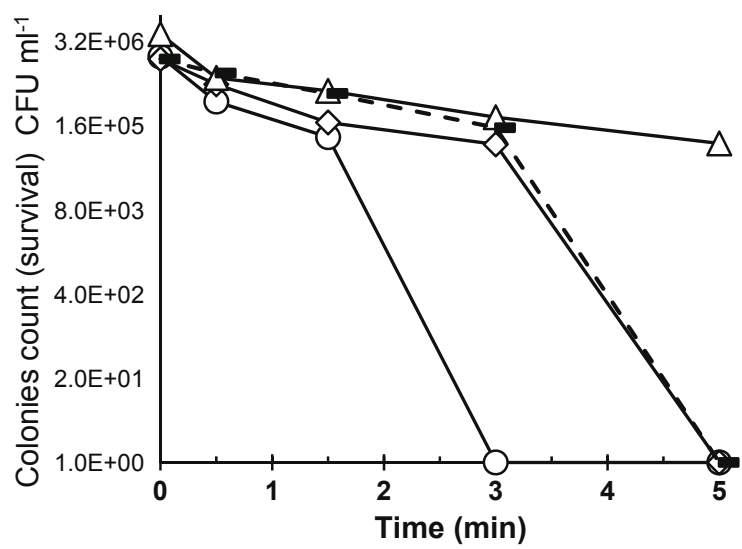

Fig. 3 Assessment of the resistance to an ethanol shock (25\% $\mathrm{v} / \mathrm{v})$, expressed as the cell counts after exposure time, for the Saccharomyces cerevisiae mezcal strains with the highest (triangle LCBG-3Y8, rhomboid LCBG-3Y5) and lowest (circle LCBG-3Y3) ethanol production on medium M3, compared to the control strain fermichamp (dashed line) 
Table 3 Amino acid substitutions in the predicted protein sequences of Hxt1p and Hxt3p for the LCBG-3Y\# mezcal strains and the fructophilic control strain Fermichamp, compared to S. cerevisiae S288c

\begin{tabular}{|c|c|c|c|}
\hline Amino acid substitution $^{\mathrm{a}}$ & $\begin{array}{l}\text { Hexose transporter Hxtlp } \\
\text { S. cerevisiae strain }\end{array}$ & Amino acid substitution $^{\mathrm{a}}$ & $\begin{array}{l}\text { Hexose transporter } H x t 3 p \\
\text { S. cerevisiae strain }\end{array}$ \\
\hline V61A & All LCBG-3Y\# strains, Fermichamp & $\mathrm{T} 200 \mathrm{~A}$ & Fermichamp $^{\mathrm{b}}$ \\
\hline $\mathrm{T} 64 \mathrm{M}$ & All LCBG-3Y\# strains, Fermichamp & L207S & All LCBG-3Y\# strains \\
\hline F79I & LCBG-3Y5 & $\mathrm{I} 209 \mathrm{~V}$ & Fermichamp $^{\mathrm{b}}$ \\
\hline F79R & LCBG-3Y8 & M324I & Fermichamp $^{\mathrm{b}}$ \\
\hline T93I & LCBG-3Y4 & L388M & Fermichamp $^{\mathrm{b}}$ \\
\hline D94E & Fermichamp & Y389W & Fermichamp $^{\mathrm{b}}$ \\
\hline F95N & Fermichamp & $\mathrm{I} 392 \mathrm{~V}$ & Fermichamp $^{\mathrm{b}}$ \\
\hline S299G & All LCBG-3Y\# strains, Fermichamp & Y398L & All LCBG-3Y\# strains \\
\hline G317D & LCBG-3Y4 & G405R & LCBG-3Y2 \\
\hline $\mathrm{T} 338 \mathrm{~K}$ & All LCBG-3Y\# strains, Fermichamp & V406L & LCBG-3Y2 \\
\hline V354L & LCBG-3Y5 & E414Q & Fermichamp $^{\mathrm{b}}$ \\
\hline F360L & LCBG-3Y2 & G415N & Fermichamp $^{\mathrm{b}}$ \\
\hline V409G & LCBG-3Y8 & V428C & All LCBG-3Y\# strains \\
\hline D418N & All LCBG-3Y\# strains, Fermichamp & $\mathrm{I} 449 \mathrm{~V}$ & Fermichamp $^{\mathrm{b}}$ \\
\hline Q419N & All LCBG-3Y\# strains, Fermichamp & L471I & Fermichamp $^{\mathrm{b}}$ \\
\hline P420G & All LCBG-3Y\# strains, Fermichamp & M563L & All LCBG-3Y\# strains \\
\hline V431C & All LCBG-3Y\# strains, Fermichamp & & \\
\hline I437L & LCBG-3Y8 & & \\
\hline E454Q & LCBG-3Y8 & & \\
\hline F456G & LCBG-3Y8 & & \\
\hline V460I & LCBG-3Y8 & & \\
\hline $\mathrm{I} 490 \mathrm{~F}$ & LCBG-3Y8 & & \\
\hline Y493F & LCBG-3Y8 & & \\
\hline G531S & Fermichamp & & \\
\hline G547S & LCBG-3Y5, LCBG-3Y8 & & \\
\hline
\end{tabular}

${ }^{a}$ Amino acid substitution positions compared to the $S$. cerevisiae S288c sequence (SGD)

b Taken from Guillaume et al. (2007)

the LCBG-3Y\# strains, nor did we find those identified in the commercial wine strains reported by Karpel et al. (2008). However, the mutations in the LCBG3Y\# strains were closely situated to those identified previously, and we found two mutations exclusively present in strain LCBG-3Y2.

\section{Discussion}

The results in media M1 and M2 allowed us to assess the metabolic differences of the $S$. cerevisiae mezcal isolates, particularly in terms of their capacity to consume fructose and produce ethanol. The ethanol yield was generally lower in the M2 (agave-like) media than in M1, except for the fructophilic strain
LCBG-3Y8, the glucophilic strain LCBG-3Y5 and the control strain Fermichamp.

As the Agave species and production techniques used to prepare mezcal differ widely in each region of Mexico where this spirit is produced, it is not surprising that the type and productivity of the yeasts found during the fermentation process are particular and unique (see the detailed review by Lappe-Oliveras et al. 2008). These yeasts are seldom analysed in terms of the genetic/productive diversity of the predominant species, $S$. cerevisiae, during the same fermentation process; comparisons are usually made amongst the most productive strains of different fermentation sites such as those of Arrizon et al. (2006) and DíazMontaño et al. (2008), where the fermentative performances and volatile production of $S$. cerevisiae strains 
obtained from various wineries were analysed. In the case of Arrizon et al. (2006), the different S. cerevisiae strains came from different must fermentations of Dasylirion (used to produce sotol from the Chihuahua state) and Agave spp. (used to produce mezcal from the Guerrero state and both tequila and raicilla from the Jalisco state); these strains were compared with those of wine strains from the Basilicata, Sicily and Campania regions in Italy and were fermented in high (medium HASF, $300 \mathrm{~g}$ of hexoses per litre), low (medium LSAF, $30 \mathrm{~g}$ of hexoses per litre) sugar agave (Agave tequilana) musts and also in grape must. These authors observed that in the most stress-inducing medium (HASF), the performance of the agave strains was higher in terms of the sugar consumption, volatile production and fermentation efficiency than the performance observed for the grape strains, highlighting the importance of the selection of a specific strain depending on the raw material used as a substrate. In the case of Díaz-Montaño et al. (2008) they compared industrial $S$. cerevisiae tequila strains from different factories in an agave-based medium adjusted at $12^{\circ}$ Brix and supplemented with $1 \mathrm{~g}$ of ammonium sulphate per litre and found that the aromatic profile diversity was higher than the kinetic performances and genetic profiles determined by RAPD. These findings are most likely because these strains have been previously selected based on high fermentation performance and the ability to produce more than $20 \mathrm{mg}$ of ethyl acetate per litre.

The fact that mezcal $S$. cerevisiae strains behaved differently in terms of hexose consumption in medium M3 $(\mathrm{G} / \mathrm{F}=1: 1)$, compared with the control strain Fermichamp, could be because the latter was isolated from a grape must fermentation and is commercially used to reactivate stuck fermentations, where the glucose concentration is typically minimal or zero and there is a high concentration of both fructose and ethanol, factors that greatly influence the fermentative capabilities of yeast (Santos et al. 2008; Arroyo-López et al. 2009). The fitted linear (fructose) and logarithmic (glucose) profiles have also been observed by Tronchoni et al. (2009), who evaluated the percentage of sugar still remaining in a Tempranillo must fermented by strain $S$. cerevisiae T73 rather than hexose consumption. Furthermore, it can easily be observed that the better a strain was able to take up the fructose, the sooner the two fitted lines intercepted (at $\mathrm{G} / \mathrm{F}=1)$; this was observed at $110 \mathrm{~h}$ (4.6 days) for the
Fermichamp strain (Fig. 2a), at $160 \mathrm{~h}$ (6.7 days) for LCBG-3Y8 (Fig. 2b) and no interception was observed for LCBG-3Y5 or LCBG-3Y3 (Fig. 2c, d).

Arrizon et al. (2006) and Berthels et al. (2004) also observed that the performance of $S$. cerevisiae strains largely depends on the fermentation substrate (agave or grape musts), the location where they were isolated, the temperature (Tronchoni et al. 2009), which was rather high in our case, the physiological state (exponential or stationary) of the inocula (Santos et al. 2008) and also on the kinetic properties of the in vivo fructose phosphorylation once it has been taken up by the yeast (Berthels et al. 2008). However, it was intriguing that the Fermichamp strain was unable to consume all of the glucose in the M3 medium, contrary to the results reported by Guillaume et al. (2007) in a synthetic must medium (MS300) with the same G/F initial ratio and concentration and a similar temperature $\left(28^{\circ} \mathrm{C}\right)$. This may be due to the lack of agitation in our fermentation experiments and the lower inoculum used in this work. The different nitrogen sources and concentrations are also important, and although the nitrogen source was used in excess here to avoid limitation, excessive supplementation has been reported to cause a decrease in the fermentation efficiency (Taillandier et al. 2007); the exact requirements for each strain have yet to be investigated. In terms of the resistance to an ethanol shock, the fructophilic mezcal strain LCBG-3Y8 was clearly superior, and the mild flocculating behaviour of this strain at the end of the exponential phase could have caused this by physically protecting the viability of the cells in the core of the yeast aggregates.

We decided to characterise the nucleotide sequences of the hexose transporters HXT1 and HXT3 and their corresponding predicted carrier proteins (Hxtp1 and Hxtp3), which have been reported to have important enological roles and in the case of Hxt3p, to have fructophilic potential in S. cerevisiae isolates (Luyten et al. 2002; Guillaume et al. 2007) as well as resistance to ethanol. According to Karpel et al. (2008), ethanol resistance is most likely linked to an ability to maintain energy levels high enough to cope with this stress. Regarding Hxt1p, the mezcal strains and Fermichamp had many of the mutations reported by Luyten et al. (2002) and Karpel et al. (2008) (Table 3), such as the S299G change found in highly fermentative strains. We also observed the mutations in positions 418-420 and 431, which are in the loop between helices 9 and 10 and presumed to have a 
functional effect because such amino acids are situated in the exofacial side of the protein and most likely interact directly with the hexose present in the medium. Additionally, Dietvorst et al. (2010) used site-specific mutation experiments to study the ligand preference of the glucose sensor Snf3, which is highly related in sequence with the transmembrane-spanning domains of the HXT genes of S. cerevisiae, and found that two conserved amino acid positions (isoleucine374 and phenylalanine-462) were critical for fructose sensing by the Snf3 protein, indicating that subtle differences are capable of changing the kinetic parameters of the transporters. Interestingly, the yeast LCBG-3Y8 presented the highest number of unique mutations in Hxtp1 towards the C-terminal side, in contrast to the other mezcal strains tested.

There were fewer amino acid mutations predicted for Hxt3p than for Hxtp1 (Table 3), and we did not find any common position between the mezcal and Fermichamp strains (Guillaume et al. 2007) or any coincidence of mutations with respect to the Hxt3p sequences reported by Karpel et al. (2008) for wine strains. Interestingly, a mutation (L207S) found in the transmembrane region 5 (TM5) of the tested mezcal strains was very near to the one reported for Fermichamp (I209V). This domain is considered critical for sugar recognition or translocation (Guillaume et al. 2007), and the change observed in our strains was from a nonpolar (leucine, aliphatic $\mathrm{R}$ groups) to a polar (serine, uncharged $\mathrm{R}$ groups) amino acid, which could be of conformational relevance for TM5; however, this relevance needs to be confirmed experimentally. Overall, the differences among the strains have also been observed by Karpel et al. (2008), who indicated that these could be the result of a rapid evolution towards more robust fermentation rates. Although this also appears likely in our case, some of the differences could be neutral mutations that define the lineage of their wild origin, as proposed by these authors.

\section{Conclusions}

Spontaneous mezcal fermentation allowed the isolation of novel native strains of $S$. cerevisiae that showed different productive phenotypes, demonstrating that these strains are attractive candidates for the fermentation of high-fructose musts. Yeasts LCBG-3Y8 and LCBG-3Y5 showed the best technological potential from the fructophilic and glucophilic point of view, due to their productive parameters and stress resistance during fermentation, respectively. Although the sequence analysis of Hxtp1 and Hxtp3 did not directly correlate with the observed productive capabilities or with ethanol resistance, it is clear that the increased capacity for glucose/fructose uptake and metabolite production cannot be solely attributed to point mutations in a specific transporter, but rather is the result of multicomponent complex transport/translocation interactions that render $S$. cerevisiae an exciting and intriguing biological system. At the genetic level, the mezcal strains are different from those referenced in the literature and are the basis for further studies of the improvement of the mezcal/agave fermentations, as well as other important alcohol fermentation products.

Acknowledgments The authors thank the financial support of the Instituto Politécnico Nacional (Grant SIP2012-1044) and of the Consejo Nacional de Ciencia y Tecnología (CONACyT, México) grant Ciencia Básica 2006 project 57576, and acknowledge the mobility support of the Mexico-France CONACyT program PCP 04/06 granted to A. A. Oliva Hernández.

\section{References}

Altschul SF, Gish W, Miller W, Myers EW, Lipman DJ (1990) Basic local alignment search tool. J Mol Biol 5:403-410

Arrizon J, Fiore C, Acosta G, Romano P, Gschaedler A (2006) Fermentation behaviour and volatile compound production by agave and grape must yeasts in high sugar Agave tequilana and grape must fermentations. Antonie Van Leeuwenhoek 89(1):181-189

Arroyo-López N, Querol A, Barrio E (2009) Aplication of a substrate inhibition model to estimate the effect of fructose concentration on the growth of diverse Saccharomyces cerevisiae strains. J Ind Microbiol Biotechnol 36:663-669

Berthels NJ, Cordero Otero RR, Bauer FF, Thevelein JM, Pretorius IS (2004) Discrepancy in glucose and fructose utilisation during fermentation by Saccharomyces cerevisiae wine yeast strains. FEMS Yeast Res 4:683-689

Berthels NJ, Cordero Otero RR, Bauer FF, Pretorius IS, Thevelein JM (2008) Correlation between glucose/fructose discrepancy and hexokinase kinetic propertis in different Saccharomyces cerevisiae wine yeast strains. Appl Microbiol Biotechnol 77:1083-1091

Buchan DW, Ward SM, Lobley AE, Nugent TC, Bryson K, Jones DT (2010) Protein annotation and modelling servers at University College London. Nucl Acids Res 38(Suppl):W563-W568

Díaz-Montaño DM, Délia ML, Estarrón-Espinosa M, Strehaiano P (2008) Fermentative capability and aroma compound production by yeast strains isolated from Agave tequilana weber juice. Enzyme Microb Technol 42:608-616 
Dietvorst J, Karhumaa K, Kielland-Brandt MC, Brandt A (2010) Amino acid residues involved in ligand preference of the Snf3 transporter-like sensor in Saccharomyces cerevisiae. Yeast 27(3):131-138

Guillaume C, Delobel P, Sablayrolles JM, Blondin B (2007) Molecular basis of fructose utilization by the wine yeast Saccharomyces cerevisiae: a mutated HXT3 allele enhances fructose fermentation. Appl Environ Microbiol 73:2432-2439

Karpel JE, Place WR, Linda F, Bisson LF (2008) Analysis of the major hexose transporter genes in wine strains of Saccharomyces cerevisiae. Am J Enol Vitic 59:265-275

Lappe-Oliveras P, Moreno-Terrazas R, Arrizón-Gaviño J, Herrera-Suárez T, García-Mendoza A, Gschaedler-Mathis A (2008) Yeasts associated with the production of Mexican alcoholic nondistilled and distilled Agave beverages. FEMS Yeast Res 8(7):1037-1052

Luyten K, Riou C, Blondin B (2002) The hexose transporters of Saccharomyces cerevisiae play different roles during enological fermentation. Yeast 19(8):713-726

Maier A, Völker B, Boles E, Furhmann GF (2002) Characterization of glucose transport in Saccharomyces cerevisiae with plasma membrane vesicles (counter transport) and intact cells (initial uptake) with single Hxt1, Hxt2, Hxt3, Hxt4, Hxt6, Hxt7 or Gal2 transporters. FEMS Yeast Res 2(4):539-550

Narváez-Zapata JA, Rojas-Herrera RA, Rodríguez-Luna IC, Larralde-Corona CP (2010) Culture-independent analysis of lactic acid bacteria diversity associated with mezcal fermentation. Curr Microbiol 61(5):444-450

Pina C, Santos C, Couto JA, Hogg T (2004) Ethanol tolerance of five non-Saccharomyces wine yeasts in comparison with a strain of Saccharomyces cerevisiae-influence of different culture conditions. Food Microbiol 21:439-447
Raeder U, Broda P (1985) Rapid preparation of DNA from filamentous fungi. Lett Appl Microbiol 1:17-20

Ramakrishnan V, Theodoris G, Bisson LF (2007) Loss of IRA2 suppresses the growth defect on low glucose caused by the Snf3 mutation in Saccharomyces cerevisiae. FEMS Yeast Res 7(1):67-77

Reifenberger E, Boles E, Ciriacy M (1997) Kinetic characterization of individual hexose transporters of Saccharomyces cerevisiae and their relation to the triggering mechanisms of glucose repression. Eur J Biochem 245(2):324-333

Saloheimo A, Rauta J, Stasyk OV, Sibirny AA, Penttilä M, Ruohonen L (2007) Xylose transport studies with xyloseutilizing Saccharomyces cerevisiae strains expressing heterologous and homologous permeases. Appl Microbiol Biotechnol 74:1041-1052

Santos J, Sousa MJ, Cardoso H, Inácio J, Silva S, SpencerMartins I, Leão C (2008) Ethanol tolerance of sugar transport, and the rectification of stuck wine fermentations. Microbiology 154:422-430

Taillandier P, Portugal F, Fuster A, Strehaiaho P (2007) Effect of ammonium concentration on alcoholic fermentation kinetics by wine yeast for high sugar content. Food Microbiol 24:95-100

Tronchoni J, Gamero A, Arroyo-López FN, Barrio E, Querol A (2009) Differences in the glucose and fructose consumption profiles in diverse Saccharomyces wine species and their hybrids during grape juice fermentation. Int $\mathrm{J}$ Food Microbiol 134:237-243

Verdugo Valdez A, Segura Garcia L, Kirchmayr M, Ramírez Rodríguez P, González Esquinca A, Coria R, Gschaedler Mathis A (2011) Yeast communities associated with artisanal mezcal fermentations from Agave salmiana. Antonie Van Leeuwenhoek 100:497-506 